NBER WORKING PAPER SERIES

\title{
ESTIMATING THE VALUE ADDED OF ATTENDING PHYSICIANS ON PATIENT OUTCOMES
}

\author{
Jason M. Fletcher \\ Leora I. Horwitz \\ Elizabeth Bradley \\ Working Paper 20534 \\ http://www.nber.org/papers/w20534
}

\author{
NATIONAL BUREAU OF ECONOMIC RESEARCH \\ 1050 Massachusetts Avenue \\ Cambridge, MA 02138 \\ October 2014
}

The research was supported in part by the Commonwealth Fund. Dr. Horwitz is supported by the National Institute on Aging (K08 AG038336) and by the American Federation for Aging Research through the Paul B. Beeson Career Development Award Program. Dr. Horwitz receives some salary support from Yale-New Haven Hospital (YNHH). We disclose that YNHH has a strategic partnership with Perahealth, the company that developed the Rothman Index used in this paper. The views expressed herein are those of the authors and do not necessarily reflect the views of the National Bureau of Economic Research.

NBER working papers are circulated for discussion and comment purposes. They have not been peerreviewed or been subject to the review by the NBER Board of Directors that accompanies official NBER publications.

(C) 2014 by Jason M. Fletcher, Leora I. Horwitz, and Elizabeth Bradley. All rights reserved. Short sections of text, not to exceed two paragraphs, may be quoted without explicit permission provided that full credit, including $\odot$ notice, is given to the source. 
Estimating the Value Added of Attending Physicians on Patient Outcomes

Jason M. Fletcher, Leora I. Horwitz, and Elizabeth Bradley

NBER Working Paper No. 20534

October 2014

JEL No. I11,I12

\begin{abstract}
$\underline{\text { ABSTRACT }}$
Despite increasing calls for value-based payments, existing methodologies for determining physicians' "value added" to patient health outcomes have important limitations. We incorporate methods from the value added literature in education research into a health care setting to present the first value added estimates of health care providers in the literature. Like teacher value added measures that calculate student test score gains, we estimate physician value added based on changes in health status during the course of a hospitalization. We then tie our measures of physician value added to patient outcomes, including length of hospital stay, total charges, health status at discharge, and readmission. The estimated value added varied substantially across physicians and was highly stable for individual physicians. Patients of physicians in the 75th versus 25th percentile of value added had, on average, shorter length of stay (4.76 vs 5.08 days), lower total costs $(\$ 17,811$ vs $\$ 19,822)$ and higher discharge health status ( $8 \%$ of a standard deviation). Our findings provide evidence to support a new method of determining physician value added in the context of inpatient care that could have wide applicability across health care setting and in estimating value added of other health care providers (nurses, staff, etc).
\end{abstract}

Jason M. Fletcher

University of Wisconsin-Madison

La Follette School of Public Affairs

1225 Observatory Drive

Madison, WI 53706

and NBER

jfletcher@lafollette.wisc.edu

Leora I. Horwitz

Department of Population Health

NYU School of Medicine

550 First Ave, TRB Room 607

New York, NY 10016

leora.horwitz@nyumc.org
Elizabeth Bradley

Yale School of Public Health

60 College Street

New Haven CT

elizabeth.bradley@yale.edu 


\section{$\underline{\text { Introduction }}$}

Estimating the value provided by health care providers and systems - to

encourage areas of value and reduce ineffective areas-remains one of the most challenging and important areas of health policy and practice in the US. Assessing value in health care settings has also become an important practical issue, with large financial implications. For example, as of 2015, the Centers for Medicare \& Medicaid Services (CMS) will adjust payments for physicians belonging to large groups to reflect the value of care provided (VanLare, Blum et al. 2012, VanLare 2012). The change at CMS is an effort to motivate physicians and the larger health care system to pursue strategies that improve patient outcomes and reduce unnecessary, costly services.

Current efforts to determine physicians’ contributions to patient outcomes have substantial shortcomings. First, risk adjustment and risk standardization methodologies using administrative data are imperfect. Clinicians and researchers have raised concerns that the use of inadequate risk adjustment could incentivize physicians to avoid the most challenging patients (Norton 1992, Dranove D 2002, Shen 2003, Werner and Asch 2005, Hayward and Kent 2008). Second, most existing measures apply to specific diseases, resulting in small sample size problems for physicians with insufficient numbers of patients per disease. Furthermore, disease-specific measures are difficult to use to infer overall value. For example, the Physician Quality Reporting System used by CMS includes 194 individual quality metrics (Centers for Medicare \& Medicaid Services 2012), making it cumbersome to interpret. Last, most current methods of measuring physician value focus on outpatient care, while hospital-based physicians now comprise one fifth of generalist physicians (Kuo, Sharma et al. 2009). 
What is needed is an estimate of physician value added that is pertinent for a comprehensive range of diseases and treatments, that appropriately risk adjusts for baseline clinical severity to mitigate adverse selection pressure, and that measures outcomes that are important to patients, such as health status and function.

In the field of education research, investigators have developed a value added methodology to isolate teacher effects on student outcomes based on change in test scores during the course of an academic year (Harris 2011) (McCaffrey 2009, Chetty 2011). We apply a similar approach to estimate the value added of physicians based on change in health status during the course of a hospitalization, adjusted for patient severity of illness and characteristics. We then estimate associations between our measure of physician value added and patient outcomes (from a hold-out sample) to further demonstrate the utility of our approach. We find modest but important impacts on patient outcomesapproximately an 8\% SD increase in health at discharge associated with assignment to a physician with a value added score in the $75^{\text {th }}$ percentile versus $25^{\text {th }}$ percentile of the distribution, as well as reductions in total costs and length of stay.

Although our measures of value added of attending physicians, like all similar measures used in the literature, are difficult to separate from the value provided by other personnel caring for the patients, the measure should be interpreted broadly to reflect all actions and decisions related to attending physicians. Our findings lay the groundwork for a new approach to support value-based payment reform that is applicable to a broad set of patient diseases and physicians.

\section{Conceptual Framework and Empirical Approach}

We extend the education literature to the hospital setting by linking changes in patient health with their specific physician during their hospitalization using a Value 
Added Model (VAM). The basic idea is that health (like educational achievement) is a cumulative process that is a function of an individual's health endowment (e.g. genetics, birth weight) and the subsequent investments and decrements to their health as they age:

$$
H_{i t}=f\left(H_{i 0}, I_{i 0} \ldots I_{i t}, E_{i 0} \ldots E_{i t}, \mu_{i t}\right)
$$

where health at time $t$ is a function of an individual's initial health ( $\left.H_{i o}\right)$, her history of investments $\left(I_{i 0} \ldots I_{i t}\right)$ (e.g. physician interactions) and decrements in health due to illness( $\left.E_{i 0} \ldots E_{i t}\right)$ as well as any positive or negative shocks in the current period $\left(\mu_{i t}\right)$.

Simplifying the relationship to be linear and focusing on investment in health gives:

$$
H_{i t}=\beta_{0} I_{i 0} \ldots+\beta_{t} I_{i t}+\delta H_{i o}+\mu_{i t}
$$

Because the data do not contain the complete history of investments and decrements to health between birth and adulthood, we need to assume a geometric distributed lag, which imposes geometric decay of the parameters, for some $\lambda$, we have $\beta_{s}=\lambda^{s} \beta_{0}$ so that the effects of all past time-varying inputs decay at the same rate over time and their influence on current health status decrease in the specified manner as their distance from the present increases. This assumption is standard in the education literature (see Guarino et al. 2012). With this assumption, we can create a simpler estimating equation:

$$
H_{i t}=\alpha_{t} I_{i t}+\lambda H_{i t-1}+\varepsilon_{i t}
$$

This estimating equation now relates patient health outcomes at discharge $\left(H_{i t}\right)$ with the physician's investments $\left(I_{i t}\right)$, adjusting for the patient's health at admission $\left(H_{i t-1}\right)$. Note that health measurements at admission include the Rothman Index (defined below) and also diagnosis codes ${ }^{2}$ and demographics.

After conditioning for their diagnosis at admission and other characteristics, $\alpha_{t}$ will indicate the association between the physician's investment and patient gains in health—-their "value added". In practice, and following the education literature, we will

2 The diagnosis codes are from the clinical classifications software (CCS) developed by the Healthcare Cost and Utilization Project (HCUP) and is used to cluster patient diagnosis into a manageable number of clinically meaningful categories-collapsing the over 14,000 ICD diagnosis code into 285 mutually exclusive categories (i.e. Tuberculosis or Burns). 
estimate equation (3) using a summary measure (Rothman Index) of patient health and estimate physician fixed effects (indicator variables for each physician in the data). ${ }^{3}$

\section{Linking Value Added with Patient Outcomes}

Taking our results from Equations 1-3 as inputs, we then ask what the effects are of being assigned a "high quality” versus a "low quality” attending physician on patients" health (e.g. Rothman Index) and hospitalization outcomes (e.g. readmission).

$$
H_{i t}=\rho \hat{I}_{i}+\pi H_{i t-1}+v_{i t}
$$

Where the outcome of patient $i$ at hospital discharge (or post-discharge) is a function of the estimated value added status of her physician ( $\left.\hat{I}_{i}\right)$ from equation (3), her baseline health status $\left(H_{i t-1}\right)$ and health shocks that are unrelated to the physician $\left(v_{i t}\right)$. The outcomes of interest will include the Rothman Index at discharge, the total costs of the hospitalization, the length of stay, the total costs per day in the hospital, and 30-day readmission for the patient. We used ordinary least squares (OLS) regression analysis for the discharge Rothman Index, total charges, and readmission outcomes and zerotruncated Poisson regression analysis for the length of stay outcome (Long and Freese 2006). The standard errors in this multivariable regression analysis were estimated using Huber/White sandwich estimator to account for clustering of patients by the attending physician (Williams 2000).

An implicit assumption underlying a causal interpretation of equation (4) is that the patients and doctors are not paired due to the patient's health at admission and the provider's value added. To test for any sorting, we will also estimate the relationship between the assigned physician's value added and the Rothman Index at hospital admission (baseline).

$$
H_{i t-1}=\psi \hat{I}_{i}+v_{i t}
$$

\footnotetext{
${ }^{3}$ Like in the education literature, we are concerned that estimates from equation (3) could be confounded by hospital practices of sorting patients to physicians. After our controls are added for patient baseline health and diagnosis, our comparison will be over sets of patients who are identical with respect to their diagnosis and admission health status but are assigned to different physicians, and we will estimate the average "adjusted value added" of each physician in the data.
} 
We detail evidence below that $\psi=0$ in our sample, conditional on diagnosis controls, which suggests a limited role of regular and purposeful sorting between physicians with high value added and the health of the patients to whom they are assigned

\section{Data}

We use patient data from all unique medical and surgical inpatients admitted to Yale-New Haven Hospital (YNHH) between July 1, 2011 and June 30, 2012. We obtained data from the hospital electronic medical record (Sunrise Clinical Manager, Allscripts) and from the hospital billing database. From the hospital billing database, we obtained dates of admission and discharge, patient age, sex, payer status (Medicare, Medicaid, other), admitting service (medicine, surgery), an indicator for admission into the intensive care unit (ICU), discharge diagnosis ${ }^{4}$, total hospital charges, and presence of any 30-day readmission. Patient outcomes included length of hospital stay, total charges, the Rothman Index on the day of discharge, and readmission to YNHH for any cause within 30 days of discharge.

From the electronic medical record, we obtained patients' health status as defined by the Rothman Index. The Rothman Index is a validated measure of health status (Rothman, Solinger et al. 2012, Bradley, Yakusheva et al. 2013, Rothman, Rothman et al. 2013, Rothman, Rothman et al. 2013, Tepas III, Rimar et al. 2013), which is calculated from vital signs, physical exam findings, laboratory results, the Braden scale for risk of skin breakdown (Bergstrom 1987), and nursing assessments of whether a minimum

\footnotetext{
${ }^{4}$ Diagnostic categories were defined using the ICD-9 code, aggregated into one of 285 mutually exclusive categories using the clinical classifications software (CCS) developed by the Healthcare Cost and Utilization Project (
} 
standard of function is met in 11 areas (cardiac, respiratory, gastrointestinal, genitourinary, neurological, skin and tissue, safety and fall risk, peripheral vascular, food and nutrition, psychosocial, musculoskeletal). ${ }^{5}$ Nursing assessments were recorded for each patient at least once per nurse shift between the time of admission and time of discharge. The Rothman Index is calculated and updated using novel proprietary software whenever new information is entered in the electronic medical record, such as when nurse assessments are entered, blood pressure is recorded, or laboratory results are reported. The Rothman Index has a range of $(-91,100)$, with higher values indicating better health.

A total of 29,857 admissions occurred in the medicine and surgery services during both study periods. Of these, 9,982 were excluded because the admission was not the first admission in our data window ${ }^{6}$, and an additional 3,688 were excluded because they were admitted by physicians who cared for fewer than 10 patients in either the first or second time period. Thus, our final analysis sample included 16,187 patients, comprised of 8,979 patients treated by 163 attending physicians in the first six-month time period and 7,208 patients treated by 163 attending physicians in the second six-month time period.

Patient characteristics and outcomes are shown in Table 1. The mean value of the Rothman Index at admission was 76.1; the mean value at discharge was 79.6 and the mean change was 3.5 (standard deviation, 17.7). The mean number of patients seen by

\footnotetext{
${ }^{5}$ For example, the neurological standard was whether the patient was alert; oriented to person, place, time and situation; and speech was coherent.

${ }^{6}$ To avoid bias due to dynamic assignment of patients to physicians (for example, if patients that had a bad experience on the first hospitalization elected different clinicians on a repeat hospitalization), we included only the first visit within the study period for each patient. In order to generate and then validate the value added measure, we split the data into two six-month periods. We excluded patients whose attending physician at discharge attended for fewer than 10 patients in each six-month period $^{6}$.
} 
the same attending physician was 46 in the first six months and 32 in the second sixmonth period.

\section{$\underline{\text { Results }}$}

Our primary independent variable of interest was physician's value added, which we estimated from a multivariable regression in which the outcome was patient health status at the time of discharge (measured by the Rothman Index at discharge), adjusted for health status at the time of admission (measured by the Rothman Index at admission), a set of patient characteristics, and an indicator variable for each attending physician in our sample. For this analysis, we used the first six-month period of data. The multivariable regression coefficients on the physician indicator variables defined the estimated value added for each physician. We adjusted the standard errors using the Huber/White sandwich estimator to account for the clustering of patients by physician (Williams 2000).

Using equation (3), estimated value added varied from -0.6 to 0.9 on the Rothman Index (standard deviation 0.26) (Table 2). Together, physician indicator dummy variables (i.e., the value added estimates for unique physicians) were highly significant (p-value $<0.001)$. Additionally, value added estimates for the same physician in the first time period and the second time period were strongly correlated (spearman correlation coefficient $r=0.59$, p-value $<0.001)^{7}$.

Physician ranking by value added scores was highly stable over time (Table 3).

Of the 41 physicians in the bottom quartile in time period one, nearly $50 \%$ were ranked in

\footnotetext{
${ }^{7}$ For example, the teaching literature finds correlations of estimated value added across adjacent school years for the same teacher of between 0.3 and 0.7 (e.g. McCaffrey et al. 2009).
} 
the bottom quartile in time period two, $83 \%$ were in the bottom two quartiles, and none was ranked in the top quartile. Similarly, of the 40 physicians in the top quartile in time period one, $65 \%$ were ranked in the top quartile in time period two, and $87.5 \%$ were in the top two quartiles (chi-square test p-value $<0.001$ ).

importantly, physician value added was not significantly associated with the Rothman Index upon admission in the first time period $(p$-value $=0.75)$ or in the second time period for patients assigned to the same physician ( $\mathrm{p}$-value $=0.82$ ), indicating no evidence of more severely ill patients being directed to physicians with higher or lower value added estimates (selection bias based on observables).

We then estimated adjusted associations between physicians' value added determined in the first time period and their patients' outcomes in the second time period (hold-out sample), including length of stay, total charges, discharge Rothman Index, and same-hospital readmission for any cause in the 30 days following discharge. We adjusted for age, age-squared, sex, service, payer, admitting diagnosis, ICU stay, and the month of admission. For ease of interpretation, we discuss average outcomes in period two for physicians in the top $75^{\text {th }}$ percentile of value added (based on period one) compared to those in the bottom $25^{\text {th }}$ percentile of value added.

Patients of physicians in the 75th versus 25th percentile of the value added had, on average, shorter length of stay (4.76 vs 5.08 days, $\mathrm{p}<0.001$ ), lower total costs $(\$ 17,811$ vs $\$ 19,822, \mathrm{p}<0.001)$ and higher discharge Rothman Index scores (80.28 vs 78.92 , $\mathrm{p}<0.001$ ) for patients in the second six-month period (Table 4). The estimated value added was not significantly associated with likelihood of readmission within 30 days (pvalue $=0.78)$. 


\section{$\underline{\text { Discussion }}$}

Our findings provide evidence to support a new method of determining the value added by individual physicians to outcomes of hospitalized patients. Though patient outcomes necessarily also reflect care provided by other team members (e.g., physicians in training, nurses, social workers, physical therapists), we were still able to demonstrate that the value added varies substantially across attending physicians and are highly stable for individual physicians across six-month time periods.

The measure of physician value added was strongly associated with key patient outcomes including length of stay, costs, and health status at discharge, providing external validity to the concept of value added as a novel measure of physician quality. Although the effect sizes were modest, they are meaningful. Specifically, a standard deviation increase in attending physician value added was associated with a reduction in total hospital charges of approximately $6 \%$ of a standard deviation, an increase in the discharge Rothman Index of approximately $8 \%$ of a standard deviation, a reduction in length of stay of approximately $4 \%$ of a standard deviation, but was not significantly associated with the likelihood of 30-day readmission to the same hospital. Understanding the specific mechanisms underlying these associations could lead to improved methods of evaluating the differing influences of physicians on key hospital outcomes.

The value added approach to determining attending physician contributions to patient outcomes has numerous advantages. The method allows physicians' added value to be estimated on the basis of every patient's health status rather than on the basis of relatively rare events such as readmission or mortality, and is therefore less sensitive to sampling variation from a small numbers of patients per physician. Value added can be 
calculated based on any measure of health status available at defined care intervals such as admission and discharge: for example, the Modified Early Warning Score (MEWS)(Subbe, Kruger et al. 2001). Physicians’ value added could also be calculated based on changes in patient-reported outcomes over time, such as quality of life, symptom burden or global health. Given that hospitals are rapidly adopting electronic health records (Desroches, Charles et al. 2013), basing quality measurement on measures of health status automatically extracted from the medical record, such as the Rothman Index (Rothman, Solinger et al. 2012, Bradley, Yakusheva et al. 2013, Rothman, Rothman et al. 2013, Rothman, Rothman et al. 2013, Tepas III, Rimar et al. 2013, Rothman Forthcoming), is increasingly feasible (Amarasingham, Moore et al. 2010, Escobar, LaGuardia et al. 2012, Johnson, Kramer et al. 2013, Liu, Turk et al. 2013, Wu, Kharrazi et al. 2013).

Our findings should be interpreted in light of several limitations. First, the value added approach attributes all systematic changes in patients' health status between admission and discharge to the assigned attending physician at discharge even though patients have a team of health care providers, potentially including multiple attending physicians, who may contribute to value added. We note that this limitation is common to all measures of physician care quality, and is likely to reduce the signal of the individual physician because other team members are often shared among attending physicians. Hence, like other measures in the literature, our measure of value added should be interpreted broadly, recognizing that such value may be also attributed to the coordination and care efforts of nurses and other staff members who regularly work with the physicians. Future research should attempt to further separate these effects into the 
value added of physicians, nurses and other staff members, much as the education literature has attempted to estimate value added of principals, teachers, and other staff members (Eberts and Stone 1988, Brewer 1993, Coelli and Green 2012, Grissom, Kalogrides et al. 2012). Second, the findings may be confounded by selection effects in which more patients with more severe illness are assigned to certain physicians in ways that are not adequately accounted for by our health status measure. To assess this potential source of bias, we examined the association between the estimated value added from the first six-month study period and the health status at admission for the same physician in the second six-month study period, which we found to be non-significant, suggesting no evidence of this bias. Nevertheless, it is possible that heterogeneity across patients could confound the analyses.

Several opportunities exist to enhance and extend our approach. Our methods can, in principle, be scaled up by merging data from multiple hospitals. This step would allow novel cross-organizational comparisons that can be used to begin to evaluate differences in hospital practices that may be linked with physician and nurse performance in increasing patient health during hospitalization. Furthermore, hospitals (or consortia of hospitals) could use these value added methods to evaluate the impacts of specific hospital policies and professional development programs in enhancing physician and nurse value added. For example, a hospital could examine whether estimates of physicians' value added increase following the completion of a professional development program. Last, hospital and medical groups could begin to consider tying reimbursement and retention decisions more explicitly to physician and nurse value added, particularly if future studies establish links with longer-term patient outcomes. 
Tables

\begin{tabular}{|c|c|c|c|}
\hline Characteristic & $\begin{array}{c}\text { Study Cohort } \\
(\mathrm{N}=16,187)\end{array}$ & $\begin{array}{c}\text { Time Period } 1 \\
(\mathrm{~N}=8,979)\end{array}$ & $\begin{array}{c}\text { Time Period } 2 \\
(\mathrm{~N}=7,208)\end{array}$ \\
\hline \multicolumn{4}{|l|}{ Age in years } \\
\hline Mean (SD) & 59 (19) & 59 (19) & $59(18)$ \\
\hline Range & 18,104 & 18,104 & 18,102 \\
\hline Female-N (\%) & $8,076(50)$ & $4,486(50)$ & $3,590(50)$ \\
\hline \multicolumn{4}{|l|}{ Primary insurance-N (\%) } \\
\hline Medicare & $7,270(45)$ & $4,116(46)$ & $3,154(44)$ \\
\hline Medicaid & $3,054(19)$ & $1,737(19)$ & $1,317(18)$ \\
\hline Other & $5,862(36)$ & $3,126(35)$ & $2,737(38)$ \\
\hline Medicine service- $-\mathrm{N}(\%)$ & $10,448(65)$ & $5,939(66)$ & $4,509(63)$ \\
\hline Any intensive care unit stay-N (\%) & $2,814(17)$ & $1,530(17)$ & $1,284(18)$ \\
\hline \multicolumn{4}{|l|}{ Admission Rothman Index } \\
\hline Mean (SD) & $76.1(18.9)$ & $75.9(18.9)$ & $76.4(18.8)$ \\
\hline Range & $-36,100$ & $-30,100$ & $-36,100$ \\
\hline \multicolumn{4}{|l|}{ Discharge Rothman Index } \\
\hline Mean (SD) & $79.6(17.0)$ & $79(17.3)$ & $80.4(16.5)$ \\
\hline Range & $-47,100$ & $-38,100$ & $-47,100$ \\
\hline \multicolumn{4}{|l|}{ Change in Rothman Index } \\
\hline Mean (SD) & $3.5(17.7)$ & $3.2(14.6)$ & $4.0(14.8)$ \\
\hline Range & $-102,94$ & $-102,94$ & $-102,90$ \\
\hline Same hospital 30-day readmission-N (\%) & $1619(10)$ & $899(11)$ & $657(8)$ \\
\hline \multicolumn{4}{|l|}{ Length of stay_-days } \\
\hline Mean (SD) & $4.9(7.7)$ & $5.1(8.3)$ & $4.7(7.0)$ \\
\hline Range & 1,266 & 1,266 & 1,166 \\
\hline \multicolumn{4}{|l|}{ Total charges (\$) per admission } \\
\hline Mean (SD) & $\$ 18,816(31,984)$ & $18,566(32,753)$ & $19,128(31,000)$ \\
\hline Range & $\$ 593-\$ 947,113$ & $\$ 941-\$ 947,113$ & $\$ 593-\$ 818,353$ \\
\hline
\end{tabular}

Notes: RI: Rothman Index. Distribution of Patient Diagnosis Codes available from the authors. 


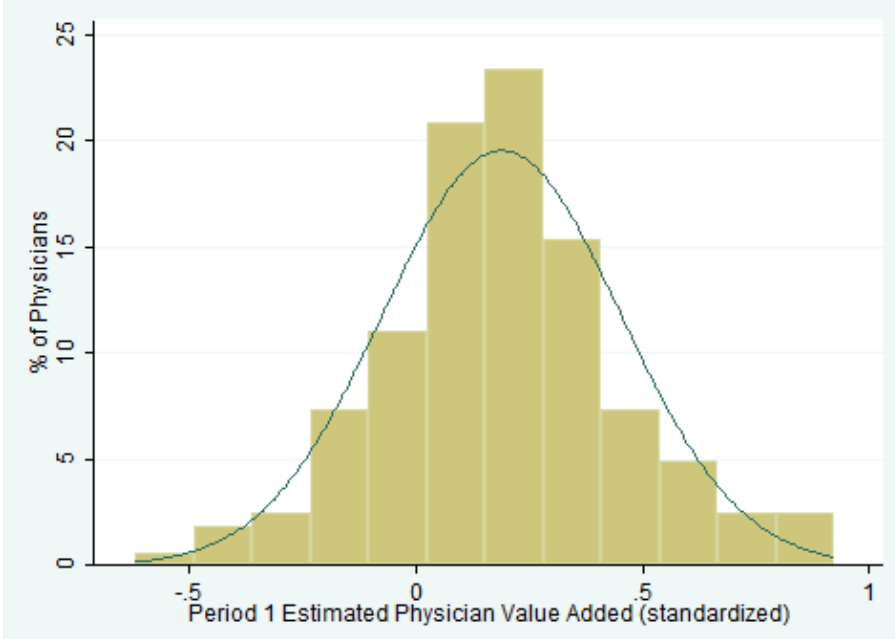

Table 2. Distribution of Estimated Physician Value Added, First Six-Months of Data.

Estimates based on 8,979 patients assigned to 163 physicians. 
Table 3: Consistency of Estimated Physician Value Added in Time Period 1 and 2

Time Period 2

Time Period 1

\begin{tabular}{|l|rrrrr|}
\hline & Quartile 1 & Quartile 2 & Quartile 3 & Quartile 4 & Total \\
\cline { 2 - 5 } Quartile 1 & 19 & 15 & 7 & 0 & 41 \\
Quartile 2 & 10 & 16 & 14 & 1 & 41 \\
Quartile 3 & 8 & 9 & 11 & 13 & 41 \\
Quartile 4 & 4 & 1 & 9 & 26 & 40 \\
& 41 & 41 & 41 & 40 & 163 \\
\hline
\end{tabular}

Notes: This figure is a transition matrix of the quartiles of estimated value added for the 163 attending physicians in the sample between the first 6 months of data and the second six months of data. 
Table 4. Estimated Associations between Physician Value Added Determined in Time Period One and Patient Outcomes in Time Period Two $(\mathrm{N}=7,208)$

\begin{tabular}{|lcccc|}
\hline & $\begin{array}{c}\text { Discharge Rothman } \\
\text { Index (SD) }\end{array}$ & $\begin{array}{c}\text { Length of } \\
\text { Stay }\end{array}$ & $\begin{array}{c}\text { Total } \\
\text { charges }\end{array}$ & $\begin{array}{c}\text { 30 Day } \\
\text { Readmission }\end{array}$ \\
Physician Value Added (SD) & $0.080^{* *}$ & $-0.110^{* *}$ & $-2,011^{* *}$ & -0.002 \\
& $(0.000)$ & $(0.004)$ & $(0.009)$ & $(0.787)$ \\
& & {$[-0.315]$} & & \\
R-squared & 0.607 & & 0.612 & \\
\hline
\end{tabular}

Notes: Robust p-values are shown in parentheses and are clustered on the discharging physician identification number. Coefficients are presented in Row 1. Marginal effects are listed in brackets for the length of stay outcome. All results use OLS regression analysis except length of stay, which uses zero-truncated Poisson regression analysis. See Table A1 for list of control variables and full results. ** $1 \%$ statistical significance. SD: standard deviation 
Appendix Table

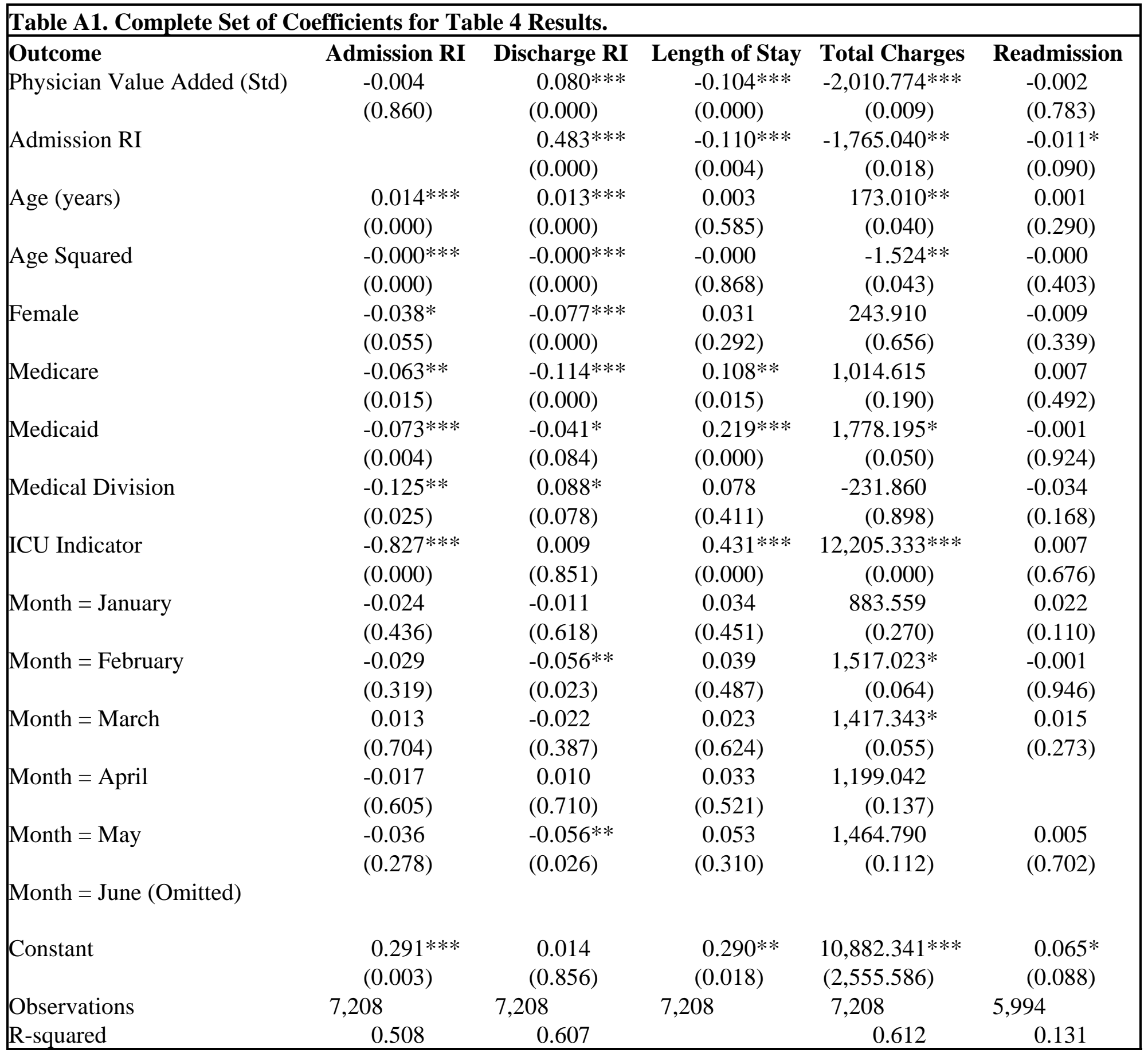

Notes: Robust p-values are shown in parentheses and are clustered on the discharging physician identification number. Coefficients are presented. All results use OLS regression analysis except length of stay, which uses zerotruncated Poisson regression analysis. The sample size for the readmission outcome is smaller because patients who were admitted in the final month of the time period were not used in the analysis due to the right censoring of the outcome. $* * * 1 \%, * * 5 \%, * 10 \%$ statistical significance. Additional Controls: Principal diagnosis indicator variables. 


\section{$\underline{\text { References }}$}

Amarasingham, R., B. J. Moore, Y. P. Tabak, M. H. Drazner, C. A. Clark, S. Zhang, W. G. Reed, T. S. Swanson, Y. Ma and E. A. Halm (2010). "An automated model to identify heart failure patients at risk for 30-day readmission or death using electronic medical record data." Med Care 48(11): 981-988.

Bergstrom, N. (1987). "The Braden Scale for predicting pressure sore risk." Nursing research 36(4): 205.

Bradley, E. H., O. Yakusheva, L. I. Horwitz, H. Sipsma and J. Fletcher (2013).

"Identifying Patients at Increased Risk for Unplanned Readmission." Medical Care 51(9): 761-766.

Brewer, D. J. (1993). "Principals and Student Outcomes: Evidence from U.S. High

Schools." Economics of Education Review 12 4: 281-292.

Centers for Medicare \& Medicaid Services. (2012). "Physician Quality Reporting System." from http://www.cms.gov/Medicare/Quality-Initiatives-PatientAssessment-Instruments/PQRS/index.html.

Chetty, R., John N. Friedman, Jonah E. Rockoff (2011). The Long Term Impacts of Teachers: Teacher Value-Added and Student Outcomes in Adulthood. NBER Working Paper 17699.

Coelli, M. and D. A. Green (2012). "Leadership Effects: School Principals and Student Outcomes." Economics of Education Review 31 1: 92-109.

Desroches, C. M., D. Charles, M. F. Furukawa, M. S. Joshi, P. Kralovec, F. Mostashari, C. Worzala and A. K. Jha (2013). "Adoption Of Electronic Health Records Grows Rapidly, But Fewer Than Half Of US Hospitals Had At Least A Basic System In 2012." Health Aff (Millwood) 32(8): 1478-1485.

Dranove D, K. D., McClellan M, Satterhwaite M (2002). "Is more information better? The effects of "report cards" on health care providers." NBER working paper no. 8697.

Eberts, R. W. and J. A. Stone (1988). "Student Achievement in Public Schools: Do Principals Make a Difference?" Economics of Education Review 7 3: 291-299. Escobar, G. J., J. C. LaGuardia, B. J. Turk, A. Ragins, P. Kipnis and D. Draper (2012). "Early detection of impending physiologic deterioration among patients who are not in intensive care: development of predictive models using data from an automated electronic medical record." LHosp Med 7(5): 388-395.

Grissom, J. A., D. Kalogrides and S. Loeb (2012). Using Student Test Scores to Measure Principal Performance. National Bureau of Economic Research, Inc, NBER Working Papers, 18568.

Harris, D. N. (2011). Value-added measures in education : what every educator needs to know. Cambridge, Mass., Harvard Education Press.

Hayward, R. A. and D. M. Kent (2008). "6 EZ steps to improving your performance: (or how to make P4P pay 4U!)." JAMA 300(3): 255-256.

HCUP. (2012). "Healthcare Cost and Utilization Project." from http://www.hcupus.ahrq.gov/toolssoftware/ccs/ccs.jsp. 
Johnson, A. E., A. A. Kramer and G. D. Clifford (2013). "A new severity of illness scale using a subset of acute physiology and chronic health evaluation data elements shows comparable predictive accuracy." Crit Care Med 41(7): 1711-1718. Kuo, Y. F., G. Sharma, J. L. Freeman and J. S. Goodwin (2009). "Growth in the care of older patients by hospitalists in the United States." N Engl J Med 360(11): 11021112. Liu, V., B. J. Turk, A. I. Ragins, P. Kipnis and G. J. Escobar (2013). "An electronic Simplified Acute Physiology Score-based risk adjustment score for critical illness in an integrated healthcare system." Crit Care Med 41(1): 41-48.

Long, J. S. and J. Freese (2006). Regression models for categorical dependent variables using Stata. College Station, Tex., StataCorp LP.

McCaffrey, D., TR Sass, JR Lockwood, and K Mihaly (2009). "The Intertemporal Variability of Teacher Effect Estimates." Education Finance and Policy. Norton, E. C. (1992). "Incentive regulation of nursing homes." L Health Econ 11(2): 105-128.

Rothman, M. J., S. I. Rothman and J. Beals (2013). "Development and validation of a continuous measure of patient condition using the Electronic Medical Record." Lournal of Biomedical Informatics 46(5): 837-848. Rothman, M. J., A. B. Solinger, S. I. Rothman and G. D. Finlay (2012). "Clinical implications and validity of nursing assessments: a longitudinal measure of patient condition from analysis of the Electronic Medical Record." BMJ Open 2(4). Rothman, M. J., Steven I Rothman, Joseph Beals IV, Alan B Solinger (Forthcoming). "The Rothman Index - A Real-Time Measure of General Patient Condition Spanning the Hospital Acuity Spectrum: Model Development and Construct Validation." BMI. Rothman, S. I., M. J. Rothman and A. B. Solinger (2013). "Placing clinical variables on a common linear scale of empirically based risk as a step towards construction of a general patient acuity score from the electronic health record: a modelling study." BMJ Open 3(5).

Shen, Y. (2003). "Selection incentives in a performance-based contracting system." Health Serv Res 38(2): 535-552.

Subbe, C. P., M. Kruger, P. Rutherford and L. Gemmel (2001). "Validation of a modified Early Warning Score in medical admissions." QJM 94(10): 521-526. Tepas III, J. J., J. M. Rimar, A. L. Hsiao and M. S. Nussbaum (2013). "Automated analysis of electronic medical record data reflects the pathophysiology of operative complications." Surgery 154(4): 918-926.

VanLare, J., J. D. Blum and P. H. Conway (2012). "Linking performance with payment: Implementing the physician value-based payment modifier." JAMA 308(20): 20892090.

VanLare, J. M., Conway, Patrick H. (2012). "Value-Based Purchasing — National Programs to Move from Volume to Value." New England Journal of Medicine 367(4): 292-295.

Werner, R. and D. Asch (2005). "THe unintended consequences of publicly reporting quality information." IAMA 293(10): 1239-1244.

Williams, R. L. (2000). "A Note on Robust Variance Estimation for Cluster-Correlated Data." Biometrics 56(2): 645-646. 
Wu, A. W., H. Kharrazi, L. E. Boulware and C. F. Snyder (2013). "Measure once, cut twice-adding patient-reported outcome measures to the electronic health record for comparative effectiveness research." L Clin Epidemiol 66(8 Suppl): S12-20. 